\title{
Transcultural Appropriation on the Son Goku Character Configuration from Dragon Ball Manga
}

\section{Apropriasi Transkultural Pada Konfigurasi Karakter Son Goku Dalam Manga Dragon Ball}

\author{
Dida Ibrahim Abdurrahman \\ Minat Studi Desain Komunikasi Visual, Jurusan Kriya Seni Rupa \\ Fakultas Seni Rupa dan Desain, Institut Seni Budaya Indonesia (ISBI Bandung) \\ Jalan Buahbatu No. 212, Bandung, INDONESIA \\ Author email: dida.ibrahim@gmail.com \\ Published: 7 September 2018
}

\begin{abstract}
Configuration of characters in a story is a representative manifestation that is able to communicate the order and value of cultural distinctiveness inherent in him. Along with the phenomenon of globalization, through the practice of appropriation, the various exclusive elements and knowledge of certain groups of society are reconstructed into new cultural entities, even if they do not originate in the space and time in which they created. The configurations Son Goku in manga (typical Japanese comic) Dragon Ball is a transcultural myth of elements in the classic Chinese novel Journey to The West mixed with the popular modern serial story of Superman from the American DC Comics and King Kong, as well as the mythology of lycanthropy from Europe. Through further investigation, the source taken in the Son Goku configuration is suspected of having a relationship with elements and knowledge of different spaces and past times (archaic), so that he is not just a popular myth, he is a collection of texts from various cultural civilizations that are scattered all over the earth.
\end{abstract}

Keywords: Transcultural Appropriation, Character Configuration, Son Goku.

\begin{abstract}
ABSTRAK
Konfigurasi karakter dalam sebuah cerita/ kisah merupakan manifestasi representatif yang mampu mengomunikasikan tatanan dan nilai dari kekhasan kebudayaan yang melekat pada dirinya. Seiring dengan fenomena globalisasi, melalui praktek apropriasi, beragam elemen ekslusif dan pengetahuan dari kelompok masyarakat tertentu direkonstruksi menjadi entitas kebudayaan baru, sekalipun bukan berasal dari ruang dan waktu dimana dia muncul/ diciptakan. Konfigurasi Son Goku dalam manga (komik khas Jepang) Dragon Ball merupakan mite transkultural dari elemen yang ada pada novel klasik asal Tiongkok yang berjudul Journey to The West yang dicampur dengan kisah populer moderen Superman dari serial DC Comics dan King Kong asal Amerika, serta mitologi likantrof asal Eropa. Melalui penelusuran lebih lanjut, sumber yang diambil dalam konfigurasi Son Goku dicurigai memiliki relasi dengan elemen dan pengetahuan dari ruang yang berbeda dan waktu yang lebih lampau (arkaik), sehingga dia tidak hanya sekedar mite populer, dia merupakan kumpulan teks dari berbagai peradaban kebudayaan yang tersebar diseluruh penjuru bumi.
\end{abstract}

Kata Kunci: Apopriasi Transkultural, Konfigurasi Karakter, Son Goku

eISSN: 2550-214X (C) 2018. The Authors. Published for Idealogy Journal of Arts and Social Science by UiTM Press. This is an Open Access article distributed under the terms of the Creative Commons Attribution-NonCommercial-NoDerivatives License (http://creativecommons.org/licenses/by-nc-nd/4.0/), which permits non-commercial re-use, distribution, and reproduction in any medium, provided the original work is properly cited, and is not altered, transformed, or built upon in any way.

\section{PENDAHULUAN}

Menurut Hera S. Walker (1998: hal. 1), integrasi elemen asing ke dalam sebuah kebudayaan tertentu merupakan proses kesadaran kemajuan budaya yang berjalan bertahap. Kemajuan tersebut tidak dapat terjadi kecuali ada alasan yang cukup untuk diterima oleh budaya yang mengadopsinya. Kutipanya atas 
Schrieke menerangkan bahwa selama masih di bawah naungan matahari yang sama, tidak ada kebaruan, yang baru merupakan kombinasi pengetahuan. Sebuah penemuan tidak dibuat dari ketiadaan, dia berakar dari pengetahuan lampau. Kutipan Walker ini memunculkan pemahaman bagaimana sebuah kebudayaan berkembang karena adanya kombinasi unsur asli dan asing. Elemen lokal masih diperlukan untuk bisa diterima integrasinya dengan elemen asing yang diadopsinya, termasuk di dalamnya mitos, legenda, dan cerita kepahlawanan yang berkembang pada kebudayaan tertentu. Berdasarkan catatan Walker, kisah kepahlawanan memiliki pola yang stereotip.

Fenomena perubahan/ reproduksi mite tersebut adalah apropriasi transkultural. Sebuah wilayah yang membaca gerakan-gerakan transformasi esensial yang dilandasi oleh dominasi, perjuangan, pertahanan, dan penolakan dari sebuah entitas kultur sebagai bagian dari ekses globalisasi budaya. Termasuk di dalamnya produk-produk visual budaya. Dia tidak lagi berbicara masalah otonomi, kesetaraan, dan pluralisme orisinalitas. Kisah-kisah legendaris dan figur- figur (karakter) yang ada di dalamnya merupakan penanda representatif akan adanya perkembangan pengetahuan (media) dalam kebudayaan masyarakat yang saling mempengaruhi.

Dalam uraian R. A. Rogers (2006: hal. 447), praktek apropriasi transkultural terbagi kedalam empat tipe: (1) Pertukaran Budaya, meliputi pertukaran simbol, artefak, ritual, genre, dan/ atau teknologi antar budaya dengan tingkat kekuatan yang hampir sama.; (2) Dominasi Budaya, penggunaan unsur-unsur budaya dominan oleh anggota budaya subordinasi dalam konteks di mana budaya dominan telah diterapkan pada budaya subordinasi, termasuk alokasi yang memberlakukan perlawanan; (3) Eksploitasi Budaya, perampasan unsur-unsur budaya subordinasi oleh budaya dominan tanpa timbal balik substantif, izin, dan/ atau kompensasi.; dan (4) Transkulturasi, unsur budaya yang diciptakan dari dan/atau oleh beberapa budaya, sehingga identifikasi budaya tunggal asal memiliki masalah, karena beberapa struktur budaya dalam dinamika globalisasi dan kapitalisme transnasional menciptakan bentuk hibrida.

Menurut catatan Audifax (2005: h. 64-65) terhadap Otto Rank, Pahlawan (Hero) memiliki pola tematik yang mengadopsi pada kisah-kisah mitologi klasik yang bisa kita temukan dalam figur-figur legendaris, seperti Herkules, Romulus, Musa, Paris. Bisa ditemukan juga pada risalah religi kenabian sebagai orang yang 'terpilih' untuk menyelamatkan umat manusia dari kegelapan/ kehancuran. Kisah penyelamatan tersebut seolah menjadi standar alur dalam beragam kisah kepahlawanan (hero). Secara sederhana pola tersebut bisa dideskripsikan dalam tahap-tahap berikut: (1) Ramalan kelahiran sang Pahlawan; (2) Kelahiran sang Pahlawan dalam satu proses ke-dewa-an, kebangsawanan, ataupun berbau kerajaan; (3) Sang Pahlawan adalah sosok yang ditinggalkan, diberikan, atau dibuang di air; (4) Ditolong dan diadopsi oleh sosok yang menggantikan orang tuanya; (5) Kembali ke tanah kelahiran ayahnya, dimana sang Pahlawan akan membuktikan keberhagaan/ kebernilaian dirinya; (6) Sang Pahlawan mengklaim hak yang inheren dengan kelahirannya dan diberi penghargaan atas jasanya; (7) Sang Pahlawan adalah anak yang terpisah dari orang tua, umumnya adalah putra dari seorang Raja.

Kisah-kisah kepahlawanan klasik sampai saat ini terus direproduksi dengan nuansa mite baru. Menurut Audifax (2005, hal. 8), mite adalah cerita dari masa lalu, dia menjelaskan esensi kehidupan dan dunia, atau mengekspresikan adanya nilai moral budaya dalam kehidupan manusia. Mite memberi perhatian pada kekuatan yang mengontrol kehidupan manusia dan relasi antara kekuatan tersebut dengan keberadaan manusia. Meski memiliki nilai religi dalam bentuk dan fungsinya, ditenggarai merupakan bentuk awal dari sejarah, sains, atau filsafat.

Reproduksi mite klasik dapat kita lihat pada film trilogi Starwars (1977, 1980, 1983), The Lords of The Ring (2001, 2002, 2003), dan The Matrix (1999, 2003, 2003) yang merujuk pada mite religi dalam perang salib, sebuah peristiwa pengambil-alihan Yerusalem didasari oleh ramalan keagamaan akan adanya perang terakhir menjelang hari kiamat, kepercayaan akan datangnya juru selamat dan pasukan khususnya. Kisah Ramayana dan Mahabharata dalam kepercayaan Hindu kuno, pengambilan kitab suci Budha dalam Journey to The West. Kisah Nabi Ibrahim dalam mencari Tuhanya, kisah Nabi Isa sang Juru Selamat yang akan diturunkan kembali ke bumi menjelang hari kiamat, dan kisah Nabi Muhammad sang penyampai pesan dalam agama Islam. Mitologi pagan Eropa serta Mesir kuno tentang 
dewa-dewa dan okultisme.

Karakter-karakter yang muncul dalam sebuah rangkaian kisah merupakan sosok yang dikonstruksi melalui atribut, karakteristik, ciri-ciri, dan keterhubungannya dengan sosok/ objek lain. Konfigurasi karakter secara keseluruhan membawa konsep ruang, waktu, tradisi, simbol-simbol, kode, konvensi, konflik, artefak, dan konstruksi lain sehingga menjadikannya sebagai subjek representatif dari beragam elemen kebudayaan sebagai penanda identifikasi dan pernyataan eksistensinya, melewati batas-batas wilayah kebudayaan dan waktu kemunculanya. Melalui praktek apropriasi transkultural, konfigurasi karakter merupakan konstruksi yang merepresentasikan keyakinan-keyakinan (beliefs), hasrat-hasrat, teori-teori, nilai-nilai, dan sebagainya.

Relasi yang saling mempengaruhi tersebut dapat dilihat dari contoh dugaan persamaan struktur fisik pada konfigurasi karakter Gatotkaca dan Ironman (Gambar 1 dan 2). Meskipun kedua karakter tersebut terpisahkan secara wilayah, dapat dilihat adanya kesamaan konfigurasi fisik. Keduanya memiliki lambang yang melekat di dadanya, memiliki kumis, memiliki kemampuan terbang, memiliki kekuatan 'besi'. Melihat waktu dan tempat kemunculanya, dari persamaan- persamaan tersebut dimungkinkan adanya asosiasi kausal.

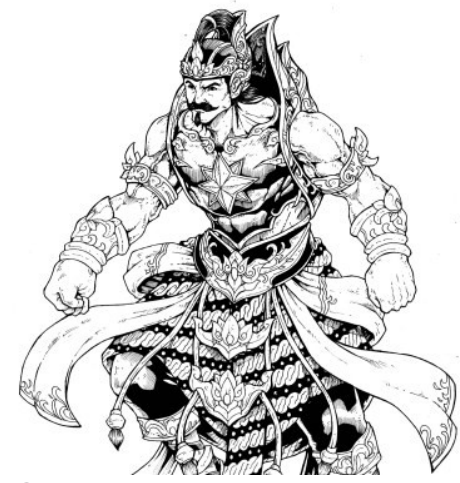

Gambar 1. Penggambaran Karakter Gatotkaca

dalam kisah Pewayangan

(Sumber: Dida Ibrahim A., 2014)

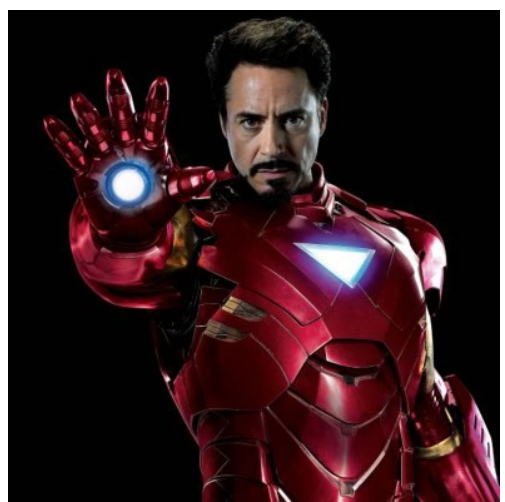

Gambar 2. Karakter Ironman dalam Kisah Komik Marvel "Ironman"

(Sumber: Google Image, 2017)

Apabila dikaji melalui pendekatan apropriasi transkultural dalam praktek karya seni, sebuah objek baru mengambil alih peran yang melekat pada objek asalnya atau yang ada dalam karya seni itu sendiri menjadi medium yang kritis, sehingga pemaknaanya telah bertransformasi dan sangat memungkinkan terjadi tarik menarik subjek secara nyata. Apropriasi budaya merupakan salah satu mekanisme pengadopsian beberapa elemen budaya tertentu oleh kelompok budaya yang berbeda. Hal ini menggambarkan adanya proses akulturasi atau asimilasi, akan tetapi dapat menyiratkan pandangan negatif terhadap akulturasi dari budaya minoritas oleh budaya yang dominan. Proses ini dapat mencakup pengenalan bentuk pakaian atau perhiasan, musik dan seni, agama, bahasa, atau perilaku sosial. Unsur-unsur tersebut 'dihapus' dari budaya aslinya, yang melekat adalah transformasi makna yang secara signifikan berbeda dari keberadaanya sejak awal. Praktek apropriasi budaya melibatkan 'perampasan' ide, simbol, artefak, gambar, suara, benda, bentuk atau gaya dari budaya lain, dari sejarah seni, budaya populer atau aspek lain yang melekat pada budaya visual maupun non-visualnya.

\section{METODE}

Tulisan ini merupakan paparan kualitatif, melalui pendekatan metode deskriptif asosiatif, diharapkan bisa menemukan kemungkinan adanya kombinasi praktek apropriasi transkultural dan mite pada objek penelitian. Dengan sampel konfigurasi Son Goku dalam manga Dragon Ball dan teknik 
penelusuran, pemilahan, dan penyimpulan data-data literatur, konfigurasi Son Goku melalui pendekatan teori transkulturasi dalam konteks praktek apropriasi, disinyalir memiliki kemungkinan adanya asosiasi kausal dengan konfigurasi dan mite Sun Gokong dalam novel Hsi Yu Chi (Journey to The West) asal Tiongkok, Superman terbitan DC Comic asal Amerika, dan mitologi kuno Eropa Likantof (Manusia Srigala). Konfigurasi yang diadopsi dalam manga Dragon Ball merupakan kombinasi dari beragam visual arkais.

\section{HASIL DAN PEMBAHASAN}

Apropriasi budaya saat ini tidak bisa terhindarkan, sehingga dalam beberapa pemahaman, seperti dalam studi budaya, kritik media, kritik retorikal, dan studi komunikasi interkultural telah dikonsep ulang menjadi sebuah pemahaman mengenai relasi radikal yang dialogis. Melalui konsep pemikiran hibriditas, apropriasi transkultural dipahami melalui kondisi historis yang spesifik, membaca fenomena dialektika transnasional dan transkultur sebagai bagian dari konsekuensi globalisasi budaya. Transkulturasi melibatkan elemen-elemen dan bentuk budaya dari berbagai sumber tanpa mengenal batasan ruang dan waktu. Mereka berinteraksi satu sama lain memproduksi bentuk baru dan merubah konvensi budaya yang sedang berjalan.

\subsection{Manga Dragon Ball (1984-1995)}

Dragon Ball merupakan komik berseri karya Akira Toriyama yang paling berpengaruh dalam sejarah manga, diterbitkan pada tahun 1984-1995. Versi Anime-nya (film kartun) dirilis melalui beragam seri: (1) Dragon Ball 1986-1989; (2) Dragon Ball Z 1989-1996); (3) Dragon Ball GT 19961997; (4) Dragon Ball Super (2015-sekarang). Manga ini bergenre Sains Fantasi dengan segmentasi dewasa, remaja, anak-anak. Karena bergenre fantasi, seting dan ploting kisah ini sangat ekletik, sosok manusia dan binatang yang bersosok manusia kerap muncul dan saling berinteraksi. Seperti hanya manga lainya yang sejaman, manga Dragon Ball kaya akan fantasi masa depan yang bertekhnologi mutakhir dan robotik, sekalipun dicampur dengan visual-visual tradisional khas Jepang.

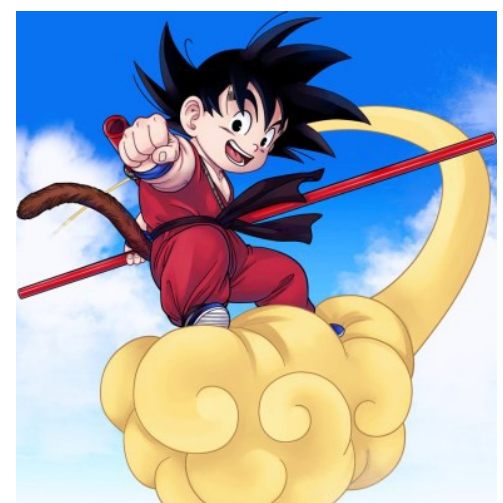

Gambar 3: Goku Kecil Menaiki Awan Kinton

(Sumber: static.comicvine.com, diakses 6 November 2017)

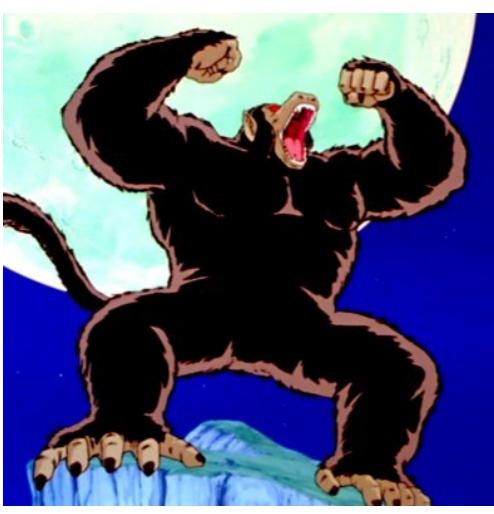

Gambar 4: Tranformasi Goku menjadi Monyet Raksasa

(Sumber: vignette2.wikia.nocookie.net, diakses 6 November 2017)

Pada sinopsis awal, Goku diceriterakan masih bayi, sangat mungil, memiliki ekor seperti monyet (Gambar 3). Diceritakan, Goku bukan bukan manusia asal bumi, dia adalah bangsa Saiya yang diselamatkan orang tuanya dari kehancuran planet asalnya Vegeta. Nama asal Goku adalah Kakarot. Di Bumi, dia diasuh oleh Gohan. Seiring waktu berjalan, dia menjadi tangguh, kuat, dan ahli bela diri. Petualanganya dimulai sejak bertemu perempuan remaja bernama Burma yang sedang berburu bola naga, kemudian bertemu dengan Uron yang berfisik babi, dan Yamucha.

Karena bukan dari bangsa Manusia, Goku memiliki keanehan berubah wujud menjadi monyet raksasa saat bulan purnama (Gambar 4). Selain ahli bertarung tangan kosong, dia dilengkapi dengan 
tongkat sakti yang bisa memanjang-memendek, membesar-mengecil, serta memiliki awan yang bisa ditunggangi. Pada satu waktu, ekor monyetnya terpotong dalam pertarungan, sehingga secara wujud, Goku terlihat seperti sosok manusia biasa. Cerita Dragon Ball cukup panjang, karena begitu populer, kisahnya diteruskan pada generasi anaknya Son Gohan dan Son Goten, dilengkapi juga dengan beragam versi yang memiliki perbedaan alur cerita.

\subsection{Praktek Apropriasi Transkultural dalam Kisah Manga Dragon Ball}

Dalam beberapa sumber, manga (komik jepang) Dragon Ball secara jelas terinspirasi oleh kisah novel klasik asal Tiongkok Hsi Yu Chi (Journey to The West). Di Indonesia, kisah tersebut dikenal melalui film seri 'Kera Sakti' (1996).

Karakter utama manga Dragon Ball adalah Goku mengambil konfigurasi Wu Kong si kera sakti, Bulma si biksu Xuanzang, Oolong sebagai Zhu Bajie, dan Yamcha sebagai Wujing. Dalam komik versi Indonesia, nama-nama karakter dikenal dengan nama Son Goku, Burma (Bulma), Uron (Oolong), dan Yamucha (Yamcha). Pengadopsian karakter tidak hanya menginspirasi konsep tokoh utama, tapi nyaris seluruh karakter. Tidak hanya konfigurasi karakter, kisah yang diangkat pada manga Dragon Ball ini juga mengadopsi alur cerita kisah Journey to The West, yang menjadi pembeda dalam kisah Dragon Ball adalah perjalanan pencarian/ pengumpulan sejumlah bola naga yang bisa mengabulkan semua permintaan.

Seperti halnya Sun Gokong, meski dengan wujud manusia berekor, Goku memiliki kekuatan sakti dengan tongkat yang bisa berubah wujud, menaiki awan terbang, dan jurus pertarungan yang bisa mengalahkan semua musuh. Son Goku digambarkan sebagai sosok yang naif, bertingkah lucu, sekaligus mengerikan.

Nama asal Goku adalah Kakarot yang mengingatkan kita pada kisah Superman yang berasal dari planet Kripton dengan nama Kal El karya Jery Siegel terbitan DC Comic asal Amerika pada tahun 1938. Dalam kisahnya-pun, Goku diadopsi oleh penduduk bumi bernama Gohan, dan akan bertemu dan bertarung dengan penduduk terakhir planet Vegeta bernama Bezita. Seperti halnya Superman, satu waktu, Goku harus berhadapan dengan bangsanya sendiri.

Penduduk planet Vegeta diceritakan memiliki keanehan, mereka bisa bertransformasi menjadi sosok kera raksasa saat bulan purnama. Tentu, kisah ini mengingatkan kita pada mitologi Eropa kuno likantrof, sosok manusia yang berubah menjadi serigala saat bulan purnama. Makhluk kera besar mengingatkan kita pada kisah King Kong yang bisa ditenangkan oleh sosok perempuan. Dalam perjalanan kisah Dragon Ball, Goku ditemani perempuan bernama Bulma.

Di sisi yang berbeda, kera merupakan transfigurasi dewa dalam kepercayaan hindu. Dalam kisah epik tradisional hindu India Ramayana dan Mahabharata dikenal sosok Hanoman. Dia merupakan figur/ karakter yang ikut menyelamatkan Shinta istri Sri Rama yang diculik oleh Rahwana dalam kisah Ramayana. Hanoman menggambarkan sosok buruk rupa dengan perilaku yang mulia dan pengabdi yang taat. Hanoman memiliki kekuatan yang sangat luar biasa, dia bisa menyusutkan tubuhnya menjadi kecil dan memasuki kerajaan Alenka saat menyelamatkan Shinta, mampu mengangkat benda seberat apapun untuk menyelesaikan tugasnya. Diceritakan dalam kisah Ramayana, dia menjadi besar dan mengangkat gunung himalaya, terbang melintasi Alenka karena tidak tahu tumbuhan obat yang ada di gunung itu untuk menyembuhkan Laksmana adik Sri Rama dari kematian. Dalam tradisi Thailand dan Indonesia, konfigurasi Hanoman digambarkan sebagai sosok kera berwarna putih (Gambar 5).

Meski memiliki kesamaan konfigurasi kera, karakter Sun Gokong (Gambar 6) berbanding terbalik dengan Hanoman. Sun Gokong merupakan sosok kera sakti dengan perangai yang sangat liar. Juga berasal dari sumber kepercayaan tradisi yang berbeda, Sun Gokong merujuk pada kepercayaan Budhis. Hanoman merupakan representasi dari ketaatan, kemuliaan perilaku, dan pengendalian diri. Sun Gokong merepresentasikan perlawanan, berperilaku kasar dan kebebasan tanpa kendali, sehingga dia 
menggunakan mahkota pengendali untuk menjaga sifat liarnya.

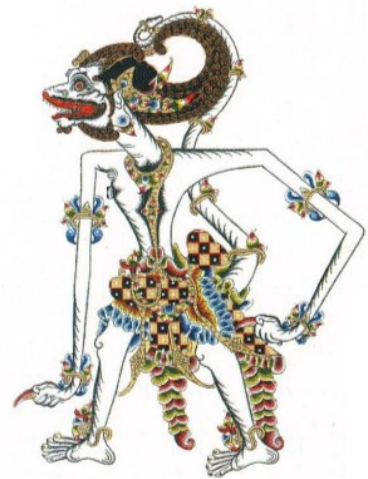

Gambar 5. Konfigurasi Hanoman versi Wayang Kulit (Sumber: wayangku.files.wordpress.com, diakses 6 November 2017)

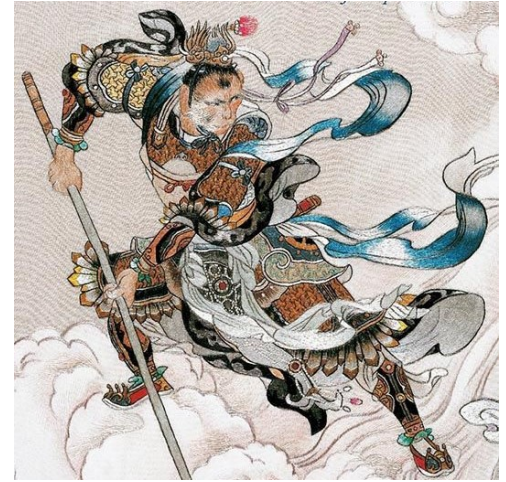

Gambar 6. Konfigurasi Sun Gokong (Sumber: i.pinimg.com, diakses 6 November 2017)

Ilmu pengetahuan dalam konteks kebudayaan tidak bisa dihilangkan, dia akan berubah menjadi kisah-kisah, legenda, dan mitos dari generasi ke generasi. Mite tidak hanya merepresentasikan tentang mimpi-mimpi, dia juga mendorong manusia untuk merancang kode-kode baru yang dihadirkan dari kombinasi pengetahuan-pengetahuan lampau (arkais). Dengan alasan tersebut bisa dikatakan bahwa semua konfigurasi karakter merupakan sebuah praktek apopriasi transkultural dari beragam sumber. Melalui pembahasan sebelumnya, konfigurasi karakter Son Goku dalam manga Dragon Ball merupakan kumpulan arkais (mitos/ mitologi) dari berbagai produk dan konfigurasi budaya yang tersebar diseluruh pelosok bumi (Bagan 1).

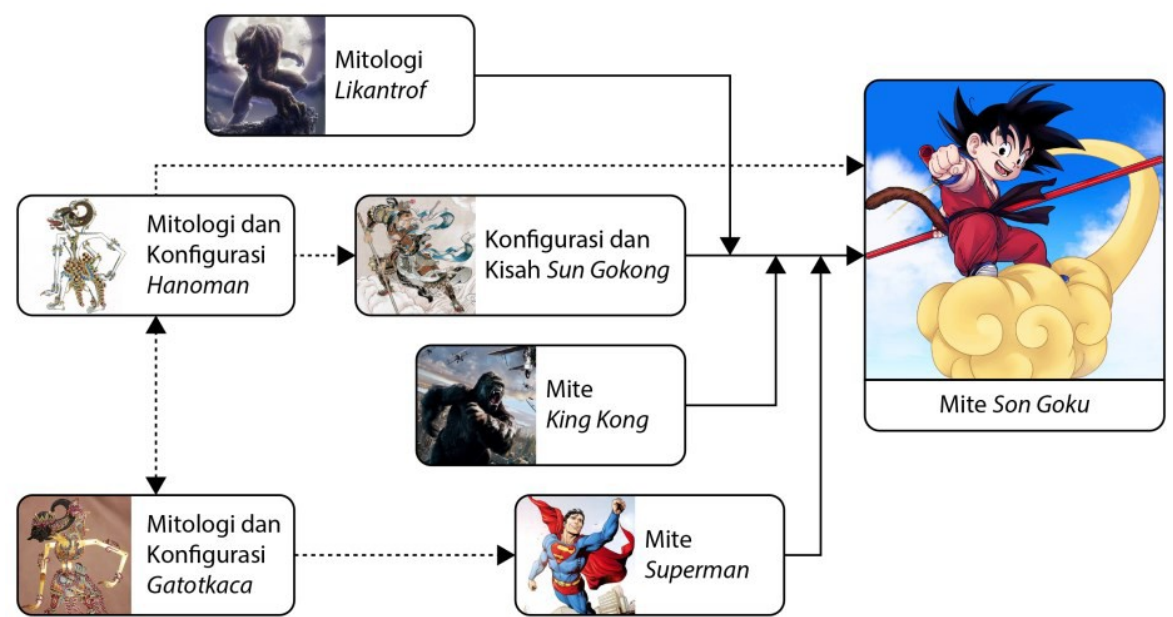

Bagan 1. Praktek Apropriasi Transkultural pada Konfigurasi Son Goku

(Sumber: Penulis, 2017)

Transformasi bentuk apropriasi transkultural dalam mite kepahlawanan tersusun dari elemenelemen budaya yang tersebar di seluruh penjuru dunia yang dalam prosesnya dipengaruhi oleh keseimbangan kekuatan ekonomi, militer, budaya, dan irisan/ persinggungan kemiripan, sehingga bentuk-bentuk mite kepahlawanan merupakan satu struktur yang dapat ditelusuri secara genealogis melalui mode kategorikal dan konfigurasi visualnya.

Kisah kepahlawanan yang stereotip muncul dalam mite Dragon Ball, diawali dengan ramalan, 'dibuang' dan diadopsi oleh sosok pengasuh, satu waktu akan menelusuri asal keberadaan dan membuktikan kebernilaian dirinya. Kisah stereotip tersebut bisa ditemukan dalam kisah nabi Musa dan mucul juga dalam mite Superman. Konfigurasi Son Goku merupakan integrasi dari elemen-elemen, simbol-simbol, konvensi, konflik, artefak dari mite Sun Gokong, sehingga dia memiliki relasi kausal 
dengan budaya asalnya. Mitologi Likantrof dan mite King Kong juga menjadi bagian dalam konstruksi mite Son Goku.

Meskipun tidak memiliki relasi kausal secara langsung, konfigurasi Son Goku telah membawa pesan dari mitologi dan konfigurasi Hanoman dan Gatotkaca dalam kisah tradisi Hindu kuno India, sehingga dia secara tidak sadar telah membawa pesan, keyakinan, dan tatanan nilai dari budaya asal yang memiliki dimensi etik dan motif spiritualisme. Dengan kata lain, mite Son Goku selain memiliki bentuk yang terintegrasi secara ikonografi arkais tradisi Tiongkok, tanpa disadari dia memiliki dimensi spiritualitas Budha yang kehadiranya dipengaruhi pula oleh tradisi Hindu kuno India.

\section{PENUTUP}

Dalam konteks praktek apopriasi transkultural dan perubahan kebudayaan, perubahan tersebut meliputi interaksi komunikatif dalam cara berpikir dan bertingkah laku (sikap). Keterikatan masyarakat dan kebudayaan meliputi proses perubahan itu sendiri, meskipun dalam realitasnya perubahan dan prosesnya dapat menyisakan ambivalensi atau secara sukarela berubah atas dasar pertahanan hidup. Di bawah payung konsep hibriditas dalam membaca fenomena dialektik budaya kontemporer, apropriasi transkultural merupakan sebuah wilayah yang akan membaca gerakan-gerakan transformasi esensial yang dilandasi oleh dominasi, perjuangan, pertahanan, dan penolakan dari sebuah entitas kultur sebagai bagian dari ekses globalisasi budaya.

Konfigurasi semacam ini bisa kita temukan dalam sampel lain, seperti karakter The Flash yang memiliki relasi konfigurasi dengan mitologi dewa Yunani Hermes, Ironman dan Superman yang diduga berelasi dengan konfigurasi Gatotkaca dalam kisah epik tradisi hindu kuno Mahabharata. Dunia paralel dalam trilogi The Matrix yang merepresentasikan ramalan arkais Zionis Yahudi. Trilogi Starwars, The Lords of The Ring, The Avenger dan Transformer yang menggambarkan adanya ramalan perang besar manusia dalam melawan kekuasaan kegelapan, sekaligus menggambarkan adanya koalisi mitologi dewa dan manusia. Ramalan akan turunya sang juru selamat dan perang besar tentunya bukan sekedar mitos, dalam kitab-kitab agama, kisah tersebut diyakini dari generasi ke generasi.

Produksi mite-mite pos moderen populer banyak menjadi perdebatan dari berbagai sumber keilmuan. Meski perlu dikaji lebih lanjut, popularitas mite-mite dan konfigurasi visual dalam produksi budaya pos moderen diduga memiliki dimensi spiritual arkais yang secara tidak sadar akan dan atau telah dibaca oleh masyarakat, tidak hanya sebatas untuk hiburan dan kesenangan, dia juga merupakan motifasi pengalaman dalam mencari kemanfaatan sosial (social benefit), petunjuk (guidance), pengawasan (surveilance), dan pertukaran sosial (social exchange). 


\section{RUJUKAN}

Audifax. (2005). Mite Harry Potter: Psikosemiotika dan Misteri Simbol Di Balik Kisah Harry Potter. Jalasutra: Yogyakarta.

Awadalla, Adel. (2004). The Prophecy and The Warnings Shines Through The Mistifying Codes of The Holy Quran: The Prophecy of World War III. Trafford Publishing: Victoria, Canada.

Dida Ibrahim A. (2013). Entitas Karakter dalam Permainan Role Playing Games (RPG).

Jurnal Seni Rupa ATRAT, Vol. 1 No. 1, Januari, hal. 26-36. Jurusan Seni Rupa STSI: Bandung. ISSN 2339-1642.

. (2014). Apopriasi Medium Wayang: Transformasi Bentuk dan Visual

Karakter pada Wayang Golek. Laporan Penelitian Dosen Pemula. PUSLIT STSI: Bandung. . (2015). Transportasi Realitas Tekstual: Orientasi Kognitif pada Game PC

Shogun II Total War. Jurnal Seni Rupa ATRAT, Vo3. 1 No. 1, Januari, hal. 51-61. Jurusan Seni Rupa STSI Bandung. ISSN 2339-1642.

Lutgendorf, Philip. (2007). Hanuman's Tale: The Message of a Divine Monkey. Oxford University Press: New York.

Mills, Margaret A., Claus, Peter J., Diamond, Sarah. (2003). South Asian Folklore: an Encyclopedia Afganistan, Bangladesh, India, Nepal, Pakistan, Sri Lanka.

Routledge: New York, London.

Rogers, Richard A. (2006). From Cultural Exchange to Transculturation: A Review and Reconceptualization of Cultural Appropiation. Communication Theory, 16, hal. 474-503. DOI: 10.1111/j.1468-2885.2006.00277.x

Rothschild, D. Aviva. (2000). Dragon Ball Vol. 1 Review. http://www.rationalmagic.com/ Accessed 6 November 2017.

Turkle, Sherry. (1997). Life on The Screen: Identity in The Age of The Internet, A Touchstone Book.

Walker, Hera S. (1998). Indigenous or Foreign: A Look at the Origins of the Monkey Hero Sun Wukong. Sino-Platonic Papers, Number 81, September.

Department of East Asian Languages and Civilizations, University of Pennsylvania: Philadelphia, USA. pdfs.semanticscholar.org, accessed 8 November 2017.

William, George M. (2003). Handbook of Hindu Mythology. Oxford University Press: New York.

Yu, Anthony C. (2006). The Monkey and The Monk: A Revised Abridgment of The Journey to the West. The University of Chicago Press: London. 